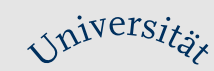

•

Jens Bohlken | Louis Jacob | Peter Schaum | Michael A. Rapp | Karel Kostev

\title{
Hip fracture risk in patients with dementia in German primary care practices
}

Suggested citation referring to the original publication:

Dementia 16 (2017) 7, pp. 853-864

DOI http://dx.doi.org/10.1177/1471301215621854

ISSN (print) 1471-3012

ISSN (online) 1741-2684

Postprint archived at the Institutional Repository of the Potsdam University in:

Postprints der Universität Potsdam

Humanwissenschaftliche Reihe ; 395

ISSN 1866-8364

http://nbn-resolving.de/urn:nbn:de:kobv:517-opus4-404526 



\title{
Hip fracture risk in patients with dementia in German primary care practices
}

\section{Jens Bohlken}

Praxis für Neurologie und Psychiatrie, Berlin, Germany

\section{Louis Jacob}

Department of Biology, École Normale Supérieure de Lyon, Lyon, France

\section{Peter Schaum}

Praxis für Chirurgie und Unfallchirurgie Kübke/Schaum, Berlin, Germany

\section{Michael A Rapp}

Department of Social and Preventive Medicine, University of Potsdam, Potsdam, Germany

\section{Karel Kostev}

IMS Health, Frankfurt am Main, Germany

\begin{abstract}
The aim was to analyze the risk of hip fracture in German primary care patients with dementia. This study included patients aged 65-90 from 1072 primary care practices who were first diagnosed with dementia between 2010 and 20I3. Controls were matched (I:I) to cases for age, sex, and type of health insurance. The primary outcome was the diagnosis of hip fracture during the three-year follow-up period. A total of 53,I56 dementia patients and 53, I 56 controls were included. A total of $5.3 \%$ of patients and $0.7 \%$ of controls displayed hip fracture after three years. Hip fracture occurred more frequently in dementia subjects living in nursing homes than in those living at home (9.2\% versus $4.3 \%)$. Dementia, residence in nursing homes, and osteoporosis were risk factors for fracture development. Antidementia, antipsychotic, and antidepressant drugs generally had no significant impact on hip fracture risk when prescribed for less than six months. Dementia increased hip fracture risk in German primary care practices.
\end{abstract}

\section{Keywords}

hip fracture, dementia, nursing homes, osteoporosis, risk factors

\section{Corresponding author:}

Karel Kostev, Epidemiology Real World Evidence Solutions, IMS HEALTH GmbH \& Co. OHG, Darmstädter, Landstraße 108 60598, Frankfurt am Main, Germany.

Email: kkostev@de.imshealth.com 


\section{Introduction}

Dementia is a psychiatric disorder caused by neurodegeneration and characterized by a progressive loss of cognitive functions leading to an alteration in the daily life of the patient (WHO, 2015). There are 47.5 million people with dementia in the world and this number is set to increase to 75.6 million by 2030 and then exceed 130 million by 2050 (WHO, 2015). In Germany, dementia affects around 1.2 million people, particularly women and the elderly, and approximately 200,000 new cases are diagnosed each year (Tunstall, 2015). The average cost related to this mental illness exceeds $€ 43,000$ per patient per year, with almost $68 \%$ of this amount paid by caregivers and families (Tunstall, 2015). Therefore, dementia has a significant impact on patients and their relatives, underlining the importance of adapted treatments and management for this disease in Germany.

Dementia has been acknowledged as a major risk factor for fall and bone fracture for decades. In 1988, Tinetti and colleagues demonstrated in 336 subjects aged 75 years and over monitored for a period of one year that cognitive impairments increased the risk of falling by five times $(\mathrm{OR}=5.0,95 \%$ CI: 1.8-13.7) (Tinetti, Speechley, \& Ginter, 1988). Another study of falls and fractures in 157 patients with dementia demonstrated that $50 \%$ of patients fell or were unable to walk during the three-year follow-up period (Buchner \& Larson, 1987). More interestingly, the same work showed that the fracture rate was equal to 69 per 1000 persons per year, whereas this rate was more than three times lower in a nondementia sample matched for sex and age (Buchner \& Larson, 1987). These results were corroborated in 2014 by Wang et al. in a study of 1408 Taiwanese patients and 7040 randomly selected Taiwanese controls (Wang et al., 2014). Indeed, these authors found that $18.75 \%$ of patients and $15.60 \%$ of controls developed hip fractures during a three-year follow-up period, and that the fracture risk associated with dementia was almost equal to 2 ( $\mathrm{HR}=1.92,95 \% \mathrm{CI}$ : 1.48-2.49). Finally, another study published the same year showed in a cohort of 66,797 patients with fracture and 133,594 controls that the overall incidence rate of dementia in subjects with fracture was $41 \%$ higher than in individuals without fractures $(6.05$ versus 4.30 per 1000 persons per year) (Tsai et al., 2014).

Although the close relationship between fracture risk and dementia has been shown by several authors in various countries (Buchner \& Larson, 1987; Reyes et al., 2014; Seitz et al., 2014; Tinetti et al., 1988; Tsai et al., 2014; Wang et al., 2014), no study has recently been conducted in Germany on this topic. Therefore, the goal of our work was to analyze the risk of hip fracture in patients with dementia in German primary care practices.

\section{Methods}

\section{Database}

The Disease Analyzer database (IMS HEALTH) compiles drug prescriptions, diagnoses, basic medical and demographic data obtained directly and in anonymous format from computer systems used in the practices of general practitioners (Becher, Kostev, \& Schröder-Bernhardi, 2009). Diagnoses (ICD-10), prescriptions (Anatomical Therapeutic Chemical Classification System), and the quality of reported data have been monitored by IMS based on a number of criteria (e.g., completeness of documentation, linkage between diagnoses and prescriptions).

In Germany, the sampling methods used for the selection of physicians' practices were appropriate to obtain a representative database of primary care practices (Becher et al., 2009). Prescription statistics for several drugs were very similar to data available from 
pharmaceutical prescription reports (Becher et al., 2009). The age groups for given diagnoses in Disease Analyzer also agreed well with those in corresponding disease registries (Becher et al., 2009).

\section{Study population}

This study included patients aged between 65 and 90 from 1072 primary care practices who were first diagnosed with dementia during the index period (January 2010 to December 2013). Follow-up lasted three years and finished in April 2015. Patients were excluded if they had been diagnosed with fracture (ICD-10: M80, S02, S12, S22, S32, S42, S52, S62, S72, S82, S92, T02, T08, T10, T12) prior to dementia diagnosis (index date). A total of 53,156 dementia patients were selected after these exclusion criteria were applied. Finally, 53,156 nondementia controls free of any fracture diagnosis prior to index date were chosen and matched (1:1) to dementia cases for age, sex, and type of health insurance (private or statutory).

\section{Study outcome}

The primary outcome was diagnosis of hip fracture (ICD-10: S72) recorded in the database between the index date and the end of follow-up. Osteoporosis (M80, M81), diabetes (E10-E14), and visual disturbances (H53, H54), which are potentially associated with fracture risk, were determined based on primary care diagnoses (ICD-10 codes). Stroke (I63, I64, G45) and heart failure (I50) were also included in the regression model. Finally, the presence of medications used in dementia therapy, such as antidementia drugs, antipsychotics, and antidepressants, was also assessed. We considered five different prescription durations for these three variables: 1, 2, 3-5, 6-10, and more than 10 months.

\section{Statistical analyses}

Descriptive statistics were obtained and differences in subject characteristics (dementia versus controls) assessed using Wilcoxon tests for paired samples or McNemar's tests. Fracture-free survival analyses were carried out using Kaplan-Meier curves and log-rank tests. Cox proportional hazard models (dependent variable: incident fracture) were used to adjust for confounders. P-values $<0.05$ were considered statistically significant. Analyses were carried out using SAS version 9.3.

\section{Results}

\section{Patient characteristics}

Patient characteristics are displayed in Table 1. A total of 53,156 subjects were included in both dementia and control groups. The mean age was 81.3 years $(\mathrm{SD}=5.9$ years) and $39.0 \%$ of subjects were men. A total of $7.3 \%$ of patients and matched controls had private health insurance. The proportion of subjects resident in nursing homes differed significantly between the dementia and control groups $(18.2 \%$ versus $3.2 \%$, p-value $<0.001)$. Diabetes, osteoporosis, and heart failure were slightly more common in nondementia subjects than in dementia patients $(30.4 \%$ versus $29.4 \%, 10.9 \%$ versus $9.8 \%$, and $21.1 \%$ versus $18.6 \%$, respectively, all p-values $<0.001$ ), whereas stroke occurred more frequently in the dementia 
Table I. Characteristics of dementia patients and matched controls in German primary care practices.

\begin{tabular}{|c|c|c|c|}
\hline Variables $^{\mathrm{a}}$ & Dementia group & Control group & P-value \\
\hline $\mathrm{N}$ & 53,156 & 53,156 & \\
\hline Age (years) & $81.3(5.9)$ & $81.3(5.9)$ & 1.000 \\
\hline Males (\%) & 39.0 & 39.0 & 1.000 \\
\hline Private health insurance (\%) & 7.3 & 7.3 & 1.000 \\
\hline Resident in nursing homes (\%) & 18.2 & 3.2 & $<0.001$ \\
\hline \multicolumn{4}{|l|}{ Co-diagnosis $^{\mathrm{b}}(\%)$} \\
\hline Diabetes & 29.4 & 30.4 & $<0.001$ \\
\hline Osteoporosis & 9.8 & 10.9 & $<0.001$ \\
\hline Stroke & 8.6 & 7.2 & $<0.001$ \\
\hline Heart failure & 18.6 & 21.1 & $<0.001$ \\
\hline \multicolumn{4}{|l|}{ Treatment ${ }^{c}(\%)$} \\
\hline Antidementia drugs & 13.5 & NA & \\
\hline Therapy duration one month & 4.4 & & \\
\hline Therapy duration two months & 1.9 & & \\
\hline Therapy duration $3-5$ months & 2.8 & & \\
\hline Therapy duration 6-10 months & 2.6 & & \\
\hline Therapy duration $>10$ months & 2.2 & & \\
\hline Antipsychotics & 29.4 & 8.3 & $<0.001$ \\
\hline Therapy duration one month & 8.9 & 3.6 & $<0.001$ \\
\hline Therapy duration two months & 4.2 & 1.2 & $<0.001$ \\
\hline Therapy duration 3-5 months & 6.0 & 1.4 & $<0.001$ \\
\hline Therapy duration $6-10$ months & 4.6 & 0.8 & $<0.001$ \\
\hline Therapy duration $>10$ months & 6.5 & 1.4 & $<0.001$ \\
\hline Antidepressants & 24.9 & 17.7 & $<0.001$ \\
\hline Therapy duration one month & 6.6 & 5.8 & $<0.001$ \\
\hline Therapy duration two months & 3.2 & 2.3 & $<0.001$ \\
\hline Therapy duration $3-5$ months & 5.2 & 3.0 & $<0.001$ \\
\hline Therapy duration 6-10 months & 4.3 & 2.1 & $<0.001$ \\
\hline Therapy duration $>10$ months & 6.1 & 4.5 & $<0.001$ \\
\hline
\end{tabular}

${ }^{a}$ Data are means (SD) or proportions (\%).

${ }^{\mathrm{b}}$ Diagnosis prior to index date or during endocrine treatment.

'Prescriptions prior to index date or during endocrine treatment.

group than in the control group $(8.6 \%$ versus $7.2 \%$, p-value $<0.001)$. Furthermore, antidementia drugs were given selectively to $13.5 \%$ of dementia patients, with $4.4 \%$ of them receiving one prescription and $9.1 \%$ at least two prescriptions. Finally, antipsychotics and antidepressants were more frequently used in dementia subjects than in matched controls $(29.4 \%$ versus $8.3 \%$ and $24.9 \%$ versus $17.7 \%$, both p-values $<0.001)$.

\section{Share of patients with fracture diagnosis}

Kaplan-Meier curves for time to hip fracture diagnosis in dementia and control groups are displayed in Figure 1. A total of $2.0 \%$ of dementia patients and $0.4 \%$ of matched controls developed hip fracture after one year of follow-up (p p <0.001). Bone fractures were presented in $5.3 \%$ of the dementia group and $0.7 \%$ of the control group after the three- 


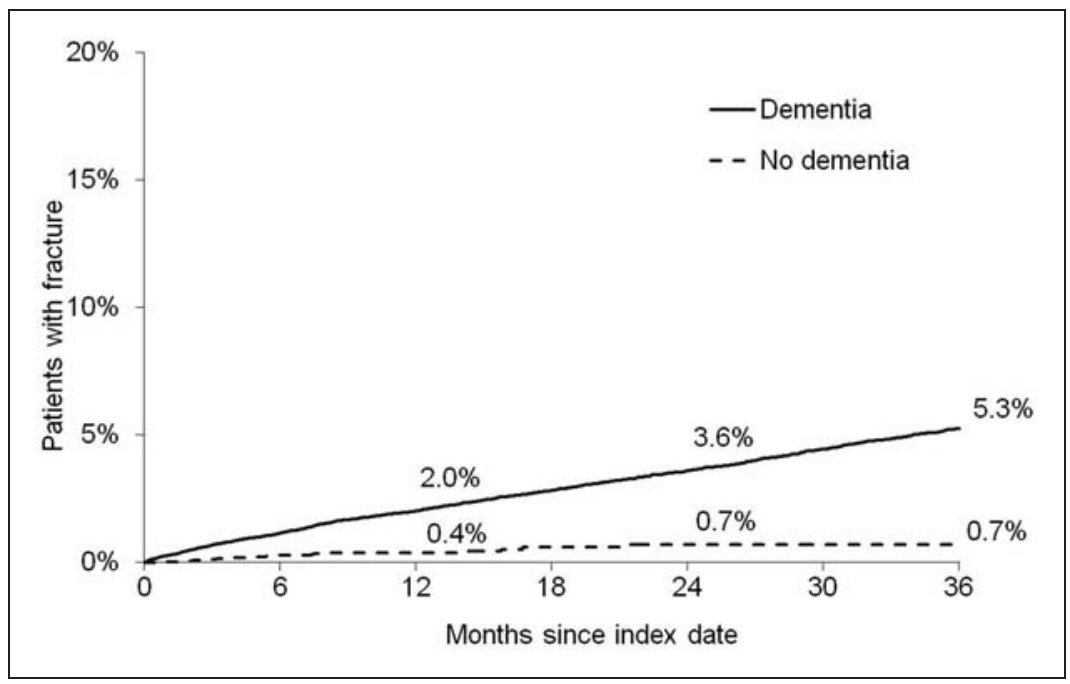

Figure I. Kaplan-Meier curves for time to hip fracture diagnosis in dementia patients and matched controls.

year follow-up period $(\mathrm{p}<0.001)$. Figure 2 shows Kaplan-Meier curves for time to hip fracture diagnosis in dementia patients in nursing home and home care settings. A total of $4.1 \%$ of dementia patients living in nursing homes and $1.5 \%$ of those living in their own homes displayed bone fracture after one year of follow-up $(\mathrm{p}<0.001)$. A total of 9.2 and $4.3 \%$, respectively, developed fractures at the end of follow-up $(\mathrm{p}<0.001)$. The results of the multivariate Cox regression model for fracture diagnosis in dementia patients and matched controls are shown in Table 2. Dementia was the strongest risk factor for hip fracture development $(\mathrm{HR}=4.52,95 \% \mathrm{CI}: 3.31-6.18$, and $\mathrm{p}$-value $<0.0001)$. Interestingly, living in a nursing home and osteoporosis also increased the risk of hip fracture diagnosis $(\mathrm{HR}=2.41,95 \%$ CI: 2.16-2.68, HR $=1.48,95 \% \mathrm{CI}: 1.29-1.70$, both p-values $<0.0001)$. Antidementia drugs did not significantly alter the risk of hip fracture when prescribed for less than 10 months ( $>10$ months: $\mathrm{HR}=0.63,95 \% \mathrm{CI}: 0.45-0.87$ and $\mathrm{p}$-value $=0.0055$ ). Antidepressants also had no significant effect when prescribed for less than six months (6-10 months: $\mathrm{HR}=0.73,95 \% \mathrm{CI}: 0.58-0.93$, p-value $=0.01$, and for $>10$ months: $\mathrm{HR}=0.54$, 95\% CI: $0.43-0.67$, p-value $<0.0001)$. Finally, antipsychotics increased the risk of hip fracture when used for one month $(\mathrm{HR}=1.20,95 \% \mathrm{CI}: 1.01-1.41$, and $\mathrm{p}$-value $=0.0339)$ and decreased this risk when used for more than 10 months (HR $=0.75,95 \%$ CI: 0.62-0.91, and p-value $<0.0001)$.

\section{Discussion}

In our study, we demonstrated that dementia was associated with an increase in the risk of hip fracture in primary care practices in Germany. We also found that dementia subjects living in nursing homes had a higher chance of developing bone fracture than dementia patients living at home. Furthermore, we showed that osteoporosis increased the odds of 


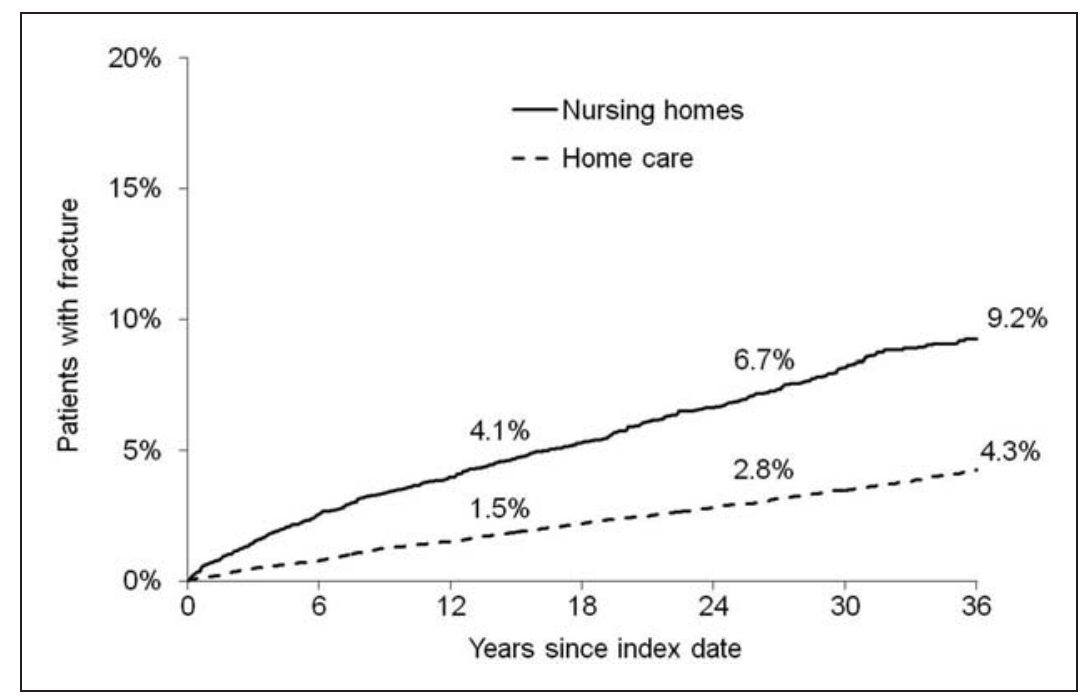

Figure 2. Kaplan-Meier curves for time to hip fracture diagnosis in dementia patients in nursing home or home care settings.

fracture. Finally, when there were less than six prescriptions, antidementia, antipsychotic, and antidepressant drugs usually had no significant effect on this risk.

The two main types of dementia are Alzheimer's disease, which accounts for $60-80 \%$ of all cases, and vascular dementia, which is found in approximately one out of five patients with dementia (Reitz, Brayne, \& Mayeux, 2011; Rizzi, Rosset, \& Roriz-Cruz, 2014). In a 2005 study of 245 subjects aged 65 years and over, Allan and colleagues found that dementia patients had a higher risk of gait and balance disorders than controls (Allan, Ballard, Burn, \& Kenny, 2005). Therefore, dementia subjects are at a higher risk of falling and developing bone fracture. Indeed, a study which included 2015 dementia patients and controls from 59 nursing homes has demonstrated that the fall rate per year was 4.05 in the dementia group as against 2.33 in the control group ( $R R=1.74,95 \%$ CI: 1.34-2.25, and p-value $<0.001$ ) (van Doorn et al., 2003). More recently, a study of 179 subjects aged over 65 conducted in the United Kingdom has shown that the incidence rate of fall was nearly eight times higher in dementia subjects than in controls (incident density ratio $=7.58$, 95\% CI: 3.11-18.5) (Allan, Ballard, Rowan, \& Kenny, 2009). Furthermore, multivariate analyses performed in the same study have demonstrated that three variables predicted fall in dementia patients: symptomatic orthostatic hypotension ( $\mathrm{HR}=2.13,95 \% \mathrm{CI}: 1.19-3.80)$, autonomic symptom score (per point $\mathrm{HR}=1.055,95 \%$ CI: 1.012-1.099), and Cornell depression score (per point HR $=1.053,95 \%$ CI: 1.01-1.099) (Allan et al., 2009).

The hip is one of the commonest sites of fracture. The link between falls and hip fractures is strong and has been studied by a number of authors. As a matter of fact, a Danish study of a retrospective cohort followed between 2000 and 2009 has shown that the incidence of hip fractures decreased over time (787-589 cases per 100,000 individuals for men, and 1758-1275 per 100,000 individuals for women), with this overall trend potentially explained by a reduction in fall-associated comorbidity (Jørgensen et al., 2014). In addition to the impact 
Table 2. Multivariate Cox regression model for hip fracture diagnosis in dementia patients and matched controls.

\begin{tabular}{|c|c|c|}
\hline Variables & Hazard ratio $(95 \% \mathrm{Cl})$ & $P$ value \\
\hline Dementia & $4.52(3.31-6.18)$ & $<0.0001$ \\
\hline Resident in nursing homes & $2.41(2.16-2.68)$ & $<0.0001$ \\
\hline Osteoporosis & $\mathrm{I} .48(1.29-1.70)$ & $<0.0001$ \\
\hline \multicolumn{3}{|l|}{ Antidementia drugs } \\
\hline Therapy duration $>10$ months $^{\mathrm{a}}$ & $0.63(0.45-0.87)$ & 0.0055 \\
\hline Therapy duration $6-10$ months $^{a}$ & $0.75(0.55-1.02)$ & 0.0616 \\
\hline Therapy duration $3-5$ months $^{a}$ & $0.98(0.75-1.27)$ & 0.8654 \\
\hline Therapy duration two months ${ }^{\mathrm{a}}$ & $1.11(0.82-1.51)$ & 0.5013 \\
\hline Therapy duration one month ${ }^{\mathrm{a}}$ & $1.01(0.81-1.27)$ & 0.9099 \\
\hline \multicolumn{3}{|l|}{ Antipsychotics } \\
\hline Therapy duration $>10$ months ${ }^{b}$ & $0.75(0.62-0.91)$ & $<0.0001$ \\
\hline Therapy duration $6-10$ months $^{b}$ & $0.97(0.78-1.20)$ & 0.7570 \\
\hline Therapy duration $3-5$ months ${ }^{\mathrm{b}}$ & $1.19(0.99-1.42)$ & 0.0660 \\
\hline Therapy duration two months ${ }^{\mathrm{b}}$ & $1.17(0.94-1.47)$ & 0.1595 \\
\hline Therapy duration one month ${ }^{\mathrm{b}}$ & $1.20(1.01-1.4 I)$ & 0.0339 \\
\hline \multicolumn{3}{|l|}{ Antidepressants } \\
\hline Therapy duration $>10$ months ${ }^{c}$ & $0.54(0.43-0.67)$ & $<0.0001$ \\
\hline Therapy duration $6-10$ months $^{c}$ & $0.73(0.58-0.93)$ & 0.0100 \\
\hline Therapy duration $3-5$ months ${ }^{c}$ & $1.04(0.86-1.26)$ & 0.1684 \\
\hline Therapy duration two months ${ }^{c}$ & $0.93(0.72-\mid .21)$ & 0.5856 \\
\hline Therapy duration one month ${ }^{c}$ & $0.92(0.76-1.11)$ & 0.3590 \\
\hline
\end{tabular}

${ }^{a}$ Reference group: patients without antidementia drug prescriptions.

${ }^{\mathrm{b}}$ Reference group: patients without antipsychotic drug prescriptions.

'Reference group: patients without antidepressant drug prescriptions.

of fall on fractures of the hip and other bones, it is important to keep in mind that fracture at one site is itself a risk factor for fracture at the contralateral site (Liu et al., 2015). As falls may be related to a psychiatric condition, there has been intensive research on the association between dementia (particularly Alzheimer's disease) and the risk of developing fracture. Buchner and Larson were among the first authors to find that the incidence rate of fracture was three times higher in patients with Alzheimer's disease than in sex- and agematched controls (Buchner \& Larson, 1987). In 1994, Melton et al analyzed the impact of Alzheimer's disease onset on fracture risk and showed that there was a twofold increase in fractures in patients newly diagnosed with Alzheimer's disease as compared with age- and sex-matched controls (Melton, Beard, Kokmen, Atkinson, \& O'Fallon, 1994). More recently, a meta-analysis including nine studies published before 2012 has examined the association between Alzheimer's disease and the risk of hip fracture, and found that dementia patients had a lower bone mineral density (standard mean difference equal to $-1.12,95 \% \mathrm{CI}:-1.34-0.90$ ) and were at a higher risk of hip fracture (for dichotomous data: $O R=1.80,95 \%$ CI: 1.54-2.11) than healthy controls (Zhao, Shen, \& Ji, 2012). Apart from these works focusing on Alzheimer's disease, several studies have been carried out on patients with other types of dementia. In 1992, Olof Johnell and colleagues found in a retrospective study of 138 subjects with Parkinson's disease and 138 controls that there 
was an increased number of fractures in the Parkinson's group $(\mathrm{n}=88)$ as compared with the control group $(n=39)(R R=2.3,95 \%$ CI: 1.6-3.3) (Johnell, Melton, Atkinson, O'fallon, \& Kurland, 1992). The greatest increase was observed for proximal femur fractures, with 20 and one cases occurring in the Parkinson's and control groups, respectively $(\mathrm{RR}=20,95 \%$ CI: 4.0->100). These results have also been confirmed in a case-control study of 174 women from New York and Philadelphia hospitals, although the fracture odds ratio associated with Parkinson's disease was higher (OR=9.4, 95\% CI: 1.2-76.1) (Grisso et al., 1991). Nonetheless, one has to keep in mind that the second study only considered hip fractures in female patients and included subjects older than those in the first study ( 80 years versus 72 years) (Grisso et al., 1991; Johnell et al., 1992).

Our work also demonstrated that the incidence of hip fractures was higher in dementia patients living in nursing homes than in those living at home. Indeed, patients living in nursing homes usually display later stages of dementia (moderate to severe), leading to greater motor dysfunction and greater gait impairment than in subjects in earlier stages (O'Keeffe et al., 1996). Thus, we concluded that home placement was a function of dementia severity. In addition to this relationship, Sato et al. demonstrated in 1998 that patients with Alzheimer's disease living in nursing homes are at a higher risk of sunlight deprivation, 25-hydroxyvitamin D deficiency, and reduction of bone mineral density (BMD) (Sato, Asoh, \& Oizumi, 1998). Later, another work found that low BMD and serum 25-OHD concentrations $<5 \mathrm{ng} / \mathrm{ml}$ with secondary hyperparathyroidism increase the risk of developing hip fracture in elderly women with dementia (Sato, Kanoko, Satoh, \& Iwamoto, 2004). Our findings are in line with this literature, as we demonstrated that living in nursing homes was a risk factor of bone fracture in dementia.

Moreover, we also showed that osteoporosis increased the chance of fracture. A recent Taiwanese study has discovered that osteoporosis increases the odds of hip fracture in dementia patients (with osteoporosis: $\mathrm{HR}=2.27,95 \% \mathrm{CI}$ : $1.28-4.01$, without osteoporosis: $\mathrm{HR}=1.84$, 95\% CI: $1.37-2.46$, both compared with the control group) (Wang et al., 2014), underlining the importance of osteoporosis treatment and management in subjects with dementia.

Our study also showed that antidementia, antipsychotic, and antidepressant drugs generally had no significant impact on hip fracture risk when prescribed for less than six months. Nonetheless, there was one exception: antipsychotics increased this risk when given to subjects for one month. By contrast, we observed that the chances of hip fracture decreased when these medications were used for more than six months. All these results must be discussed carefully, since several authors have found that such treatments have negative effects on fracture risk. Indeed, in 2009, Gill et al. analyzed the relationship between cholinesterase inhibitors, which are commonly prescribed to treat dementia, and adverse effects associated with syncope, and demonstrated that hip fractures are more frequent among patients receiving these molecules (HR $=1.18,95 \%$ CI: 1.04-1.34) (Gill et al., 2009). More recent studies with various designs and performed in different countries have returned similar results, corroborating the intriguing relationship between antidementia/antipsychotic drugs and bone fracture (Bakken et al., 2013; Eimar et al., 2013; Tamimi et al., 2012). Nonetheless, most of these works have not focused to a significant extent on the impact of therapy duration on the risk of bone fracture (Bolton et al., 2008; Liperoti et al., 2007; Ray, Griffin, Schaffner, Baugh, \& Melton, 1987). Therefore, although these drugs initially increase the odds of developing bone fractures, it is still possible that adverse effects disappear after several months and that treatment becomes more effective, 
leading to a decreased risk of falling and fractures in patients with dementia. A recent trial has shown that Donepezil improves gait in participants with mild Alzheimer's disease (Montero-Odasso et al., 2015). Since agitation and depressive symptoms increase fall risk, successful and well-tolerated antidepressant therapy could reduce this risk (Kvelde et al., 2015). Thus, this hypothesis could explain why antidementia, antipsychotic, and antidepressant drugs protected against hip fracture when there were given for more than six months.

This study was subject to several limitations. The major limitation is related to the diagnoses performed by primary care physicians, as neither dementia nor bone fracture can be diagnosed fully. Several factors potentially impacting fracture risk were also missing (i.e. decreased bone density and muscle mass, nutritional problems, or physical inactivity). We did not assess a dose relationship. Furthermore, patients were observed retrospectively in only one practice. Finally, if patients visited another doctor-which is common in Germany - this visit would not be documented.

We showed that dementia increased the risk of hip fracture in primary care practices in Germany. Living in nursing homes also impacted the incidence of fracture. Therefore, German patients with dementia need personalized treatments and management, particularly involving psychiatrists and surgeons or orthopedics, in order to decrease the comorbidity associated with bone fractures.

\section{Declaration of Conflicting Interests}

The author(s) declared no potential conflicts of interest with respect to the research, authorship, and/or publication of this article.

\section{Funding}

The author(s) received no financial support for the research, authorship, and/or publication of this article.

\section{References}

Allan, L. M., Ballard, C. G., Burn, D. J., \& Kenny, R. A. (2005). Prevalence and severity of gait disorders in Alzheimer's and non-Alzheimer's dementias. Journal of the American Geriatrics Society, 53(10), 1681-1687. DOI:10.1111/j.1532-5415.2005.53552.x.

Allan, L. M., Ballard, C. G., Rowan, E. N., \& Kenny, R. A. (2009). Incidence and prediction of falls in dementia: A prospective study in older people. PLOS ONE, 4(5), e5521. DOI:10.1371/ journal.pone.0005521.

Bakken, M. S., Engeland, A., Engesæter, L. B., Ranhoff, A. H., Hunskaar, S., \& Ruths, S. (2013). Increased risk of hip fracture among older people using antidepressant drugs: Data from the Norwegian Prescription Database and the Norwegian Hip Fracture Registry. Age and Ageing, 42(4), 514-520. DOI:10.1093/ageing/aft009.

Becher, H., Kostev, K., \& Schröder-Bernhardi, D. (2009). Validity and representativeness of the "Disease Analyzer" patient database for use in pharmacoepidemiological and pharmacoeconomic studies. International Journal of Clinical Pharmacology and Therapeutics, 47(10), 617-626.

Bolton, J. M., Metge, C., Lix, L., Prior, H., Sareen, J., \& Leslie, W. D. (2008). Fracture risk from psychotropic medications: A population-based analysis. Journal of Clinical Psychopharmacology, 28(4), 384-391. DOI:10.1097/JCP.0b013e31817d5943. 
Buchner, D. M., \& Larson, E. B. (1987). FALLS and fractures in patients with Alzheimer-type dementia. JAMA, 257(11), 1492-1495. DOI:10.1001/jama.1987.03390110068028.

Eimar, H., Perez Lara, A., Tamimi, I., Márquez Sánchez, P., Gormaz Talavera, I., Rojas Tomba, F.,... Tamimi, F. (2013). Acetylcholinesterase inhibitors and healing of hip fracture in Alzheimer's disease patients: A retrospective cohort study. Journal of Musculoskeletal and Neuronal Interactions, 13(4), 454-463.

Gill, S. S., Anderson, G. M., Fischer, H. D., Bell, C. M., Li, P., Normand, S.-L. T., \& Rochon, P. A. (2009). Syncope and its consequences in patients with dementia receiving cholinesterase inhibitors: A population-based cohort study. Archives of Internal Medicine, 169(9), 867-873. DOI:10.1001/ archinternmed.2009.43.

Grisso, J. A., Kelsey, J. L., Strom, B. L., Chiu, G. Y., Maislin, G., O’Brien, L. A., ... Kaplan, F. (1991). Risk factors for falls as a cause of hip fracture in women. The Northeast Hip Fracture Study Group. The New England Journal of Medicine, 324(19), 1326-1331. DOI:10.1056/NEJM199 105093241905.

Johnell, O., Melton, L. J., Atkinson, E. J., O'fallon, W. M., \& Kurland, L. T. (1992). Fracture risk in patients with parkinsonism: A population-based study in Olmsted County, Minnesota. Age and Ageing, 21(1), 32-38. DOI:10.1093/ageing/21.1.32.

Jørgensen, T. S. H., Hansen, A. H., Sahlberg, M., Gislason, G. H., Torp-Pedersen, C., Andersson, C., \& Holm, E. (2014). Falls and comorbidity: The pathway to fractures. Scandinavian Journal of Public Health, 42(3), 287-294. DOI:10.1177/1403494813516831.

Kvelde, T., Lord, S. R., Close, J. C. T., Reppermund, S., Kochan, N. A., Sachdev, P., ... Delbaere, K. (2015). Depressive symptoms increase fall risk in older people, independent of antidepressant use, and reduced executive and physical functioning. Archives of Gerontology and Geriatrics, 60(1), 190-195. DOI:10.1016/j.archger.2014.09.003.

Liperoti, R., Onder, G., Lapane, K. L., Mor, V., Friedman, J. H., Bernabei, R., \& Gambassi, G. (2007). Conventional or atypical antipsychotics and the risk of femur fracture among elderly patients: Results of a case-control study. The Journal of Clinical Psychiatry, 68(6), 929-934.

Liu, S., Zhu, Y., Chen, W., Sun, T., Cheng, J., \& Zhang, Y. (2015). Risk factors for the second contralateral hip fracture in elderly patients: A systematic review and meta-analysis. Clinical Rehabilitation, 29(3), 285-294. DOI:10.1177/0269215514542358.

Melton, L. J., Beard, C. M., Kokmen, E., Atkinson, E. J., \& O’Fallon, W. M. (1994). Fracture risk in patients with Alzheimer's Disease. Journal of the American Geriatrics Society, 42(6), 614-619. DOI:10.1111/j.1532-5415.1994.tb06859.x.

Montero-Odasso, M., Muir-Hunter, S. W., Oteng-Amoako, A., Gopaul, K., Islam, A., Borrie, M.,... Speechley, M. (2015). Donepezil improves gait performance in older adults with mild Alzheimer's disease: A phase II clinical trial. Journal of Alzheimer's Disease, 43(1), 193-199. DOI:10.3233/JAD-140759.

O’Keeffe, S. T., Kazeem, H., Philpott, R. M., Playfer, J. R., Gosney, M., \& Lye, M. (1996). Gait disturbance in Alzheimer's disease: A clinical study. Age and Ageing, 25(4), 313-316.

Ray, W. A., Griffin, M. R., Schaffner, W., Baugh, D. K., \& Melton, L. J. (1987). Psychotropic drug use and the risk of hip fracture. The New England Journal of Medicine, 316(7), 363-369. DOI:10.1056/ NEJM198702123160702.

Reitz, C., Brayne, C., \& Mayeux, R. (2011). Epidemiology of Alzheimer disease. Nature Reviews Neurology, 7(3), 137-152. DOI:10.1038/nrneurol.2011.2.

Reyes, C., Estrada, P., Nogués, X., Orozco, P., Cooper, C., Díez-Pérez, A., ...Prieto-Alhambra, D. (2014). The impact of common co-morbidities (as measured using the Charlson index) on hip fracture risk in elderly men: a population-based cohort study. Osteoporosis International: $A$ Journal Established as Result of Cooperation between the European Foundation for Osteoporosis and the National Osteoporosis Foundation of the USA, 25(6), 1751-1758. DOI:10.1007/s00198014-2682-9. 
Rizzi, L., Rosset, I., \& Roriz-Cruz, M. (2014). Global epidemiology of dementia: Alzheimer's and vascular types. BioMed Research International, 2014, e908915. DOI:10.1155/2014/908915.

Sato, Y., Asoh, T., \& Oizumi, K. (1998). High prevalence of vitamin D deficiency and reduced bone mass in elderly women with Alzheimer's disease. Bone, 23(6), 555-557.

Sato, Y., Kanoko, T., Satoh, K., \& Iwamoto, J. (2004). Risk factors for hip fracture among elderly patients with Alzheimer's disease. Journal of the Neurological Sciences, 223(2), 107-112. DOI:10.1016/j.jns.2004.03.033.

Seitz, D. P., Gill, S. S., Gruneir, A., Austin, P. C., Anderson, G. M., Bell, C. M., \& Rochon, P. A. (2014). Effects of dementia on postoperative outcomes of older adults with hip fractures: A population-based study. Journal of the American Medical Directors Association, 15(5), 334-341. DOI:10.1016/j.jamda.2013.12.011.

Tamimi, I., Ojea, T., Sanchez-Siles, J. M., Rojas, F., Martin, I., Gormaz, I.,... Tamimi, F. (2012). Acetylcholinesterase inhibitors and the risk of hip fracture in Alzheimer's disease patients: A casecontrol study. Journal of Bone and Mineral Research: The Official Journal of the American Society for Bone and Mineral Research, 27(7), 1518-1527. DOI:10.1002/jbmr.1616.

Tinetti, M. E., Speechley, M., \& Ginter, S. F. (1988). Risk factors for falls among elderly persons living in the community. New England Journal of Medicine, 319(26), 1701-1707. DOI:10.1056/ NEJM198812293192604.

Tsai, C.-H., Chuang, C.-S., Hung, C.-H., Lin, C.-L., Sung, F.-C., Tang, C.-H., .. Chung, C.-J. (2014). Fracture as an independent risk factor of dementia: A nationwide population-based cohort study. Medicine, 93(26), e188. DOI:10.1097/MD.0000000000000188.

Tunstall. (2015). Germany dementia statistics. Retrieved from http://www.alzheimers-support.com.

van Doorn, C., Gruber-Baldini, A. L., Zimmerman, S., Hebel, J. R., Port, C. L.Baumgarten, M. Epidemiology of Dementia in Nursing Homes Research Group. (2003). Dementia as a risk factor for falls and fall injuries among nursing home residents. Journal of the American Geriatrics Society, 51(9), 1213-1218.

Wang, H.-K., Hung, C.-M., Lin, S.-H., Tai, Y.-C., Lu, K., Liliang, P.-C., ...Chang, L.-C. (2014). Increased risk of hip fractures in patients with dementia: a nationwide population-based study. BMC Neurology, 14, 175. DOI:10.1186/s12883-014-0175-2.

WHO (2015) 10 facts on dementia. Retrieved from http://www.who.int.

Zhao, Y., Shen, L., \& Ji, H.-F. (2012). Alzheimer's disease and risk of hip fracture: A meta-analysis study. The Scientific World Journal, 2012, e872173. DOI:10.1100/2012/872173.

Jens Bohlken is a resident psychiatrist in Berlin (Germany) with focus on the therapy of dementia patients. He graduated in medicine and sociology in Frankfurt am Main and Marburg. His main research areas are dementia, health services research, and pharmacoepidemiology.

Louis Jacob is presently studying medicine at the university of Paris Descartes (France). In 2015, he obtained his masters in biology at the École Normale Supérieure de Lyon (France). Additionally he works on different research projects in the field of epidemiology of chronic diseases on the university of Marburg (Germany).

Peter Schaum is a resident surgeon and orthopedist in Berlin (Germany) with focus on the traumatology.

Michael A Rapp completed his medical training at Humboldt University Berlin and his doctoral training in psychology at the Max-Planck-Institute for Human Development in 
Berlin, Germany. His main research focus is on neurobiological and behavioral correlates of aging cognition, with a focus on psychosocial and behavioral determinants of cognitive aging, risk factors for dementia, and prevention. He is now a full Professor for Social and Preventive Medicine at the University of Potsdam, Germany.

Karel Kostev is a senior epidemiology research manager at IMS Health in Frankfurt (Germany). He graduated in sociology and statistics from the University of Freiburg, done a doctor's degree in evidence-based medicine in the University of Leipzig. He has been working for 13 years by IMS and has extensive experiencing in the management and performing epidemiological analysis using observational data. Actually he is additionally a professor for medical sciences at the Fresenius University of Idstein, Germany. 